\title{
Tuberculous Spondylitis after Percutaneous Vertebroplasty: Misdiagnosis or Complication?
}

\author{
Jung Hoon Kang ${ }^{1}$, Hyun-Sook $\mathrm{Kim}^{2}$, Seok Won Kim ${ }^{3}$ \\ Departments of Rehabilitation ${ }^{I}$, Neurosurgery ${ }^{3}$, College of Medicine, Chosun University, Gwangju, Republic of Korea \\ Department of Internal Medicine, Soonchunhyang University, College of Medicine, Seoul, Korea
}

So far, there have been few previous reports of tuberculous spondylitis occurring after percutaneous vertebroplasty. We report an unusual case of tuberculous spondylitis diagnosed after percutaneous vertebroplasty in a patient who had a history of pulmonary tuberculosis for the first time. A 58-year-old woman, who had a history of complete recovery from pulmonary tuberculosis six years previously, was hospitalized due to severe back pain after a fall. Radiological studies revealed a fresh compression fracture at the T12 thoracic vertebra. The back pain improved dramatically, and the patient was discharged two days after the vertebroplasty. However, cold sweats and a low grade fever with severe back pain developed four weeks after the procedure. Magnetic resonance imaging revealed a severe kyphosis and the T11-T12 disc space had collapsed with heterogeneous signal intensity. The results of the culture of the biopsy specimens were negative, and did not lead to identification of the causative micro-organism. However, the polymerase chain reaction for Mycobacterium tuberculosis was positive. Treatment for tuberculous spondylitis was started and she underwent posterior fusion and instrumentation from T9-L2 after the markers for infection returned to normal. After surgical intervention, the pain improved and the kyphotic deformity was corrected.

Key Words: Tuberculous spondylitis - Percutaneous vertebroplasty

\section{INTRODUCTION}

Percutaneous vertebroplasty has become a common option for the treatment of osteoporotic compression fractures because of its high success rate and ability to relieve pain rapi$\mathrm{dly}^{2}$. Despite wide application due to its simplicity, it is not without complications. The procedure related complications include extravasation of bone cement, pulmonary embolism and adjacent compression fractures. Although rare, an infected ver tebroplasty can occur after percutaneous vertebroplasty ${ }^{8,16,17}$. However, there has been no prior report of tuberculous spondylitis occurring after a percutaneous vertebroplasty. Here, an

\footnotetext{
- Received: May 6, 2013 - Revised: June 23, 2013

- Accepted: June 25, 2013

Corresponding Author: Seok Won Kim, MD, PhD

Department of Neurosurgery, School of Medicine, Chosun University,

588, Seosuk-dong, Dong-gu, Gwangju-city, 501-717, Republic of Korea

Tel: +82-62-220-3126, Fax: +82-62-227-4575

E-mail: ns64902@hanmail.net/chosunns@chosun.ac.kr
}

This study was supported by research funds from chosun university hospital 2014 unusual case of tuberculous spondylitis diagnosed after percutaneous vertebroplasty in a patient who had a history of complete recovery from pulmonary tuberculosis six years previously is reported.

\section{CASE REPORT}

A 58-year-old woman, who had a history of complete recovery from pulmonary tuberculosis six years previously, was hospitalized for severe back pain after a fall. Plain radiographs and magnetic resonance imaging of the thoracic spine revealed a fresh compression fracture at the T12 thoracic vertebra (Fig. 1). Bone densitometry indicated that the spine density was below average; the mean spinal T-score was -3.98. Physical examination demonstrated marked tenderness on palpation of the T12 region. Except for the incapacitating pain, the vital signs were stable and there was no evidence of infection. The white blood cell (WBC) count was 6,900 cells $/ \mathrm{mm}^{3}$ (normal range 3,000-10,500 cells $/ \mathrm{mm}^{3}$ ). A hematological analysis demonstrated that erythrocyte sedimentation rate (ESR) of $12 \mathrm{~mm} / \mathrm{hr}$ and C-reactive protein (CRP) of $0.5 \mathrm{mg} / \mathrm{dL}$, which were all within normal range. The pain relief was refractory to medical 

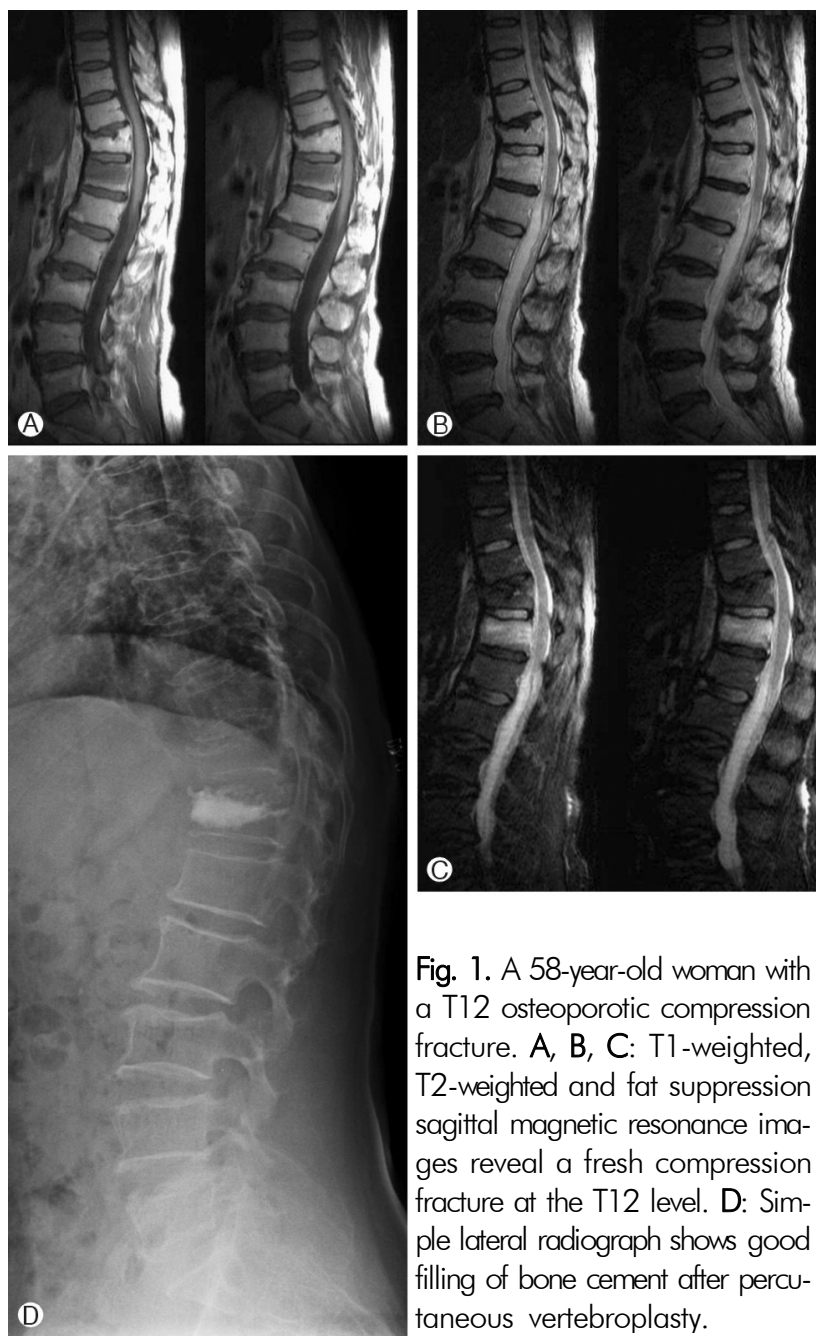

Fig. 1. A 58-year-old woman with a T12 osteoporotic compression fracture. A, B, C: T1-weighted, T2-weighted and fat suppression sagittal magnetic resonance images reveal a fresh compression fracture at the T12 level. D: Simple lateral radiograph shows good filling of bone cement after percutaneous vertebroplasty.

treatment for 2 weeks; therefore, vertebroplasty was performed and there were no intraoperative complications. Antibiotic prophylaxis was not administered before the procedure. The back pain improved dramatically, and the patient was discharged two days after the procedure. However, three weeks after the vertebroplasty, the pain gradually worsened despite administration of analgesic agents; the patient was readmitted four weeks later. Moreover, the patient reported intermittent fever with cold sweats. At the time of re-admission, the patient had a low grade fever $37.5^{\circ} \mathrm{C}$. Hematological investigation revealed a mild leukocytosis with a total WBC count of 11,000 cells $/ \mathrm{mm}^{3}$, elevation of the erythrocyte sedimentation rate (ESR) to $42 \mathrm{~mm} / \mathrm{h}$ (normal range $<30 \mathrm{~mm} / \mathrm{h}$ ) and a C-reactive protein (CRP) concentration of $2.05 \mathrm{mg} / \mathrm{dL}$ (normal range $<0.8$ $\mathrm{mg} / \mathrm{dL}$ ). Radiography and computed tomographic scanning revealed severe kyphosis, and that the disc space at the T11-T12 level had collapsed (Fig. 2). MRI also showed heterogeneous signal intensity with the spondylitis (Fig. 3). Initially, the patient was impressed with a pyogenic spondylitis, and percuta-

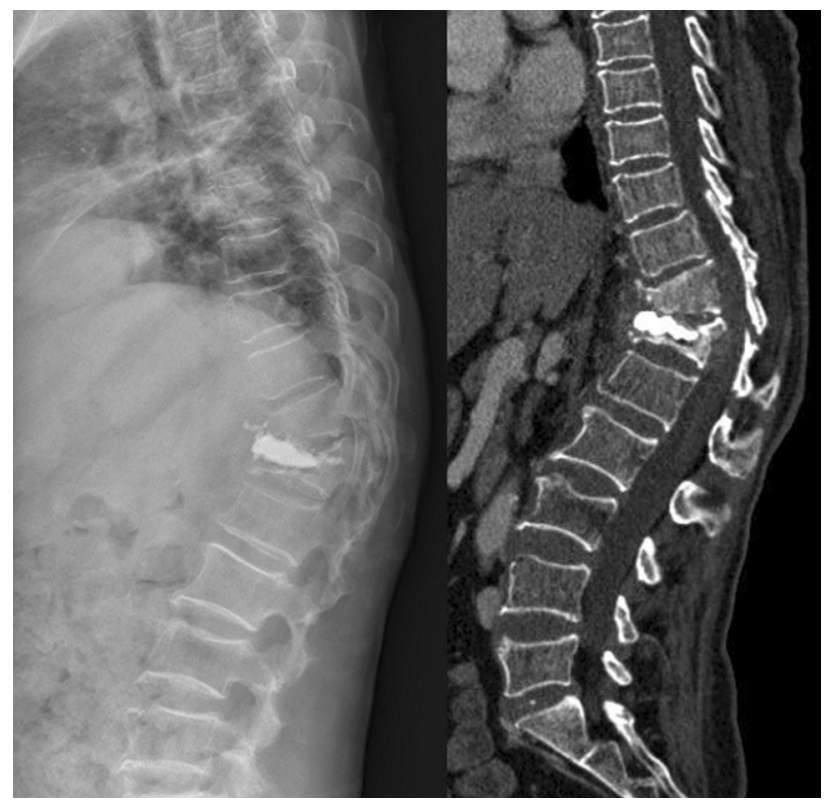

Fig. 2. Simple lateral radiograph and computed tomographic scan at 4 weeks after percutaneous vertebroplasty show aggravated kyphotic changes.

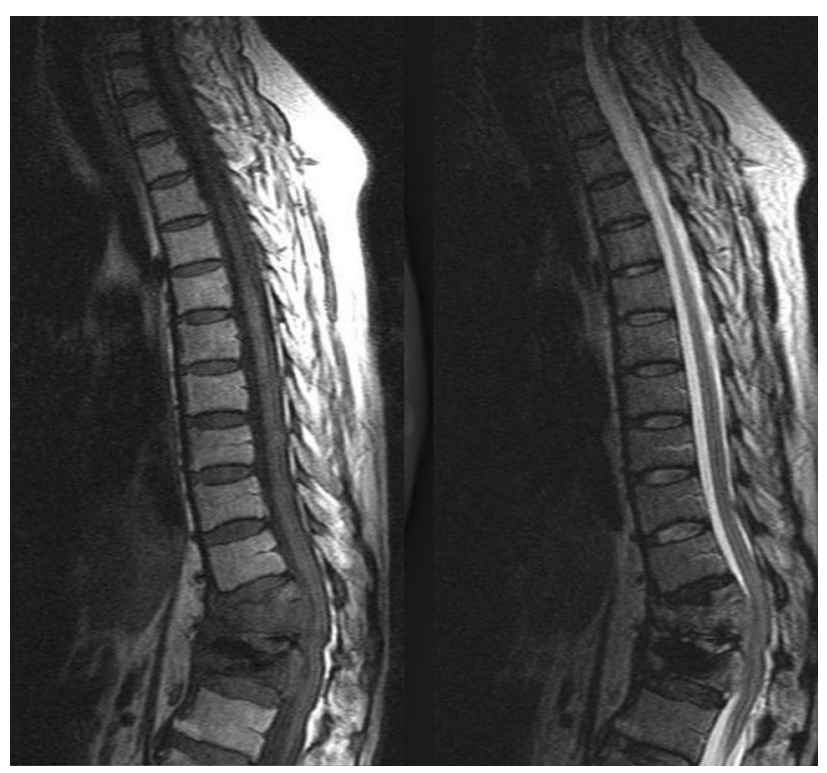

Fig. 3. T1-weighted and T2-weighted sagittal magnetic resonance images at 4 weeks after percutaneous vertebroplasty. Infectious spondylitis was apparent at the $\mathrm{T} 11$ and $\mathrm{T} 12$ levels.

neous needle biopsy from the T11 and T12 vertebrae was performed. The patient was treated with antibiotics empirically before the results of the culture were available. However, the culture of the biopsy specimens was negative and did not lead to the identification of the causative micro-organism, including acid fast bacilli. However, the polymerase chain reaction (PCR) test results, specific for Mycobacterium tubercu- 


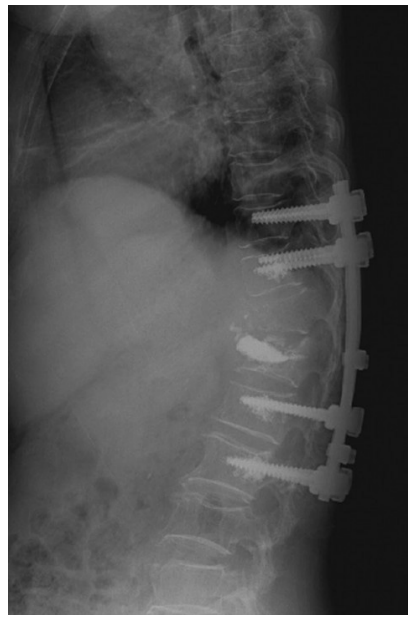

Fig. 4. Simple lateral radiograph of the thoracolumbar spine at 14 months after posterior instrumentation and fusion shows implanted hardware and improved kyphosis.

losis, were positive for three of the four specimens (one from T11 and two from T12). Medication for tuberculosis was started with the diagnosis of tuberculous spondylitis. After three weeks of tuberculosis drug therapy, the ESR and CRP decreased to nearly the normal range ( 30 and 0.38 , respectively). However, the patient was not able to walk independently because of persistent pain and aggravated kyphosis. The patient underwent posterior fusion and instrumentation from T9 to L2 without neural decompression (Fig. 4). After surgery, pain relief was achieved. The medication for tuberculosis was continued for 14 months. By 20 months after the surgery, the patient could ambulate independently without difficulty and complained only of back stiffness when walking.

\section{DISCUSSION}

Percutaneous vertebroplasty is a widely accepted treatment for painful osteoporotic compression fractures; it usually provides patients with immediate pain relief. However, long term results have shown a number of complications associated with this popular procedure. These complications are mainly related to migration of cement into the venous system, neural foramina, and posterior spinal canal as well as the generation of cement emboli ${ }^{912)}$. Infections after vertebroplasty are rare; most cases are related to systemic infection prior to the procedure. The patients with infections may be predisposed to develop spondylitis, especially at sites where foreign bodies are retained after hematological dissemination ${ }^{1,15)}$. To date, there has been only one case of tuberculous spondylitis reported in association with percutaneous vertebroplasty; but the patient presented with several risk factors for tuberculosis (immunosuppressive treatment, liver transplantation and hereditary hemochromatosis $)^{3)}$. This was different from the case presented here. The present patient had the past history of pulmonary tuberculosis. In fact, we do not know exact etiology of present tuberculous spondylitis after percutaneous vertebroplasty. It was possible that back pain presented as an initial symptom of tuberculous spondylitis. However, she stated recent traumatic history and showed severe osteoporosis on bone mineral densitometry. Based on these findings, we deduced that this case would be osteoporotic compression fracture and performed percutaneous vertebroplasty without bone marrow biopsy. Regretful thing in this patient was the abscence of bone biopsy before percutaneous vertebroplasty. If there were positive results of tuberculous spondylitis, we should not have performed percutaneous vertebroplasty. Indeed, there is possibility of tuberculous spondylitis being initially misdiagnosed as benign compression fracture in spite of evident history of slip down. Although MRI scan is the most accurate imaging study, it still may be difficult to differentiate between tuberculous spondylitis and compression fracture in some cases. Mycobacterium tuberculosis might spread hematogenously and could seed any organ and became latent if the T-cell mediated immunity of the host was sufficiently competent. When immunity has become attenuated due to aging or disease, the latent Mycobacterium tuberculosis may be reactivated and CD4 + T-lymphocytes play a pivotal role in combating the invading intracellular bacteria ${ }^{6}$. Scanga et al. reported that depletion of $\mathrm{CD} 4+\mathrm{T}$-lymphocytes in a mouse model resulted in a rapid reactivation of previously dormant Mycobacterium tuberculosis, contributing to an augmented bacterial load and exacerbating the tuberculosis ${ }^{14)}$. The progression of tuberculous spondylitis is usually insidious and slow. The main symptom, back pain, is not specific, and frequently results in a delayed diagnosis resulting in neurological deficits and more significant vertebral destruction. The clinical presentation together with the radiological appearance of the spine and a positive tuberculin test may suggest tuberculous spondylitis. However, a definitive diagnosis of tuberculous spondylitis is based on the pathological findings. Unfortunately, culture results require more than two or three weeks and usually have a low sensitivity of $50 \%$. Lee et al..$^{10)}$ reported positive culture results in only 27 out of 47 patients of tuberculous spondylitis (62\%). In our patient, bacterial culture tests for Mycobacterium tuberculosis, with the specimens obtained by needle biopsy, did not reveal the causative bacterium. However, PCR technology was a helpful method for expediting the diagnosis and treatment by amplifying DNA in specimens. Park et al. ${ }^{13)}$ used this technique in 28 patients diagnosed clinically with tuberculosis with the pathological findings of chronic but not granulomatous inflammation; there were 10 positive results in the study and they concluded that PCR technology was helpful for diagnosing such patients. Mycobacterium tuberculosis was likely responsible for the infection of the pa- 
tient reported here. This is based on the positive PCR results for Mycobacterium tuberculosis and the rapid improvement of the markers of infection with the treatment for tuberculosis. Kim and Jung et al. ${ }^{5,7}$ reported that a well-defined, abnormal paraspinal signal; a thin, smooth abscess with peripheral enhancement; subligamentous extension to multiple levels, and involvement of the thoracic vertebrae are main characteristics of tuberculous spondylitis rather than pyogenic spondylitis. The current patient underwent posterior fusion with instrumentation due to persistent pain caused by severe kyphotic changes. $\mathrm{Ha}$ et al. ${ }^{4)}$ evaluated the differences in adherence and biofilm formation between Staphylococcus aureus and Mycobacterium tuberculosis on various implant surfaces. Many experimental studies have suggested that Mycobacte- rium tuberculosis, unlike bacteria, have low adherence to stainless steel and forms less polysaccharide biofilm. Therefore, the use of implants in the presence of spinal tuberculous spondylitis is theoretically safe ${ }^{11)}$. As the correct diagnosis and adequate treatment is essential, spine surgeons should consider this disease entity to avoid any misdiagnosis or complication. Active investigation including microbiological and preoperative bone biopsy is of utmost importance.

\section{CONCLUSION}

This case illustrates that although rare, activated tuberculous spondylitis by Mycobacterium tuberculosis should be considered as a possible complication of percutaneous vertebroplasty, especially if the patient has a history of previous pulmonary tuberculosis. Careful preoperative diagnostic trials including bone biopsy are indispensible to correctly and PCR analysis for Mycobacterium tuberculosis may be a useful diagnostic method in cases with negative culture result on biopsy specimens.

\section{REFERENCES}

1. Alfonso Olmos M, Silva Gonz?lez A, Duart Clemente J, Villas Tom C: Infected vertebroplasty due to uncommon bacteria solved surgically: a rare and threatening life complication of a common procedure: report of a case and a review of the literature. Spine 31:770-773, 2006

2. Amar AP, Larsen DW, Esnaashari N, Albuquerque FC, Lavine SD, Teitelbaum GP: Percutaneous transpedicular polymethyl- methacrylate vertebroplasty for the treatment of spinal compression fractures. Neurosurgery 49:1105-1114, 2001

3. Bouvresse S, Chiras J, Bricaire F, Bossi P: Pott's disease occurring after percutaneous vertebroplasty: an unusual illustration of the principle of locus minoris resistentiae. J Infect 53:251253, 2006

4. Ha KY, Chung YG, Ryoo SJ: Adherence and biofilm formation of Staphylococcus epidermidis and Mycobacterium tuberculosis on various spinal implants. Spine 30:38-43, 2005

5. Jung NY, Jee WH, Ha KY, Park CK, Byun JY: Discrimination of tuberculous spondylitis from pyogenic spondylitis on MRI. AJR Am J Roentgenol 182:1405-1410, 2004

6. Kaufmann SH: How can immunology contribute to the control of tuberculosis? Nat Rev Immunol 1:20-30, 2001

7. Kim SW, Lee SM, Shin H: Preoperative gadolinium-enhanced magnetic Resonance images on infectious spondylitis. J Korean Neurosur Soc 38:355-358, 2005

8. Kwon KY, Kong DS, Kim ES, Eoh W: Pyogenic Spondylitis After Vertebroplasty. Korean J Spine 2(1):56-59, 2005

9. Lee BJ, Lee SP, Yoo TY: Paraplegia as a complication of percutaneous vertebroplasty with polymethylmethacrylate: A case report. Spine 27:419-422, 2002

10. Lee KY, Sohn SK, Hwang KS: Comparison of pyogenic and tuberculous spondylitis. J Korean Soc Spine Surg 6:443-450, 1999

11. Oga M, Arizono T, Takasita M, Sugioka Y: Evaluation of the risk of instrumentation as a foreign body in spinal tuberculosis. Clinical and biologic study. Spine 18:1890-1894, 1993

12. Padovani B, Kasriel O, Brunner P, Peretti-Viton P: Pulmonary embolism caused by acrylic cement: a rare complication of percutaneous vertebroplasty. AJNR Am J Neuroradiol 20:375-377, 1999

13. Park DY, Kim JY, Choi KU, Lee JS, Lee CH, Sol MY, Suh KS: Comparison of polymerase chain reaction with histopathologic features for diagnosis of tuberculosis in formalin-fixed, paraffin-embedded histologic specimens. Arch Pathol Lab Med 127:326-330, 2003

14. Scanga CA, Mohan VP, Yu K, Joseph H, Tanaka K, Chan J, Flynn JL: Depletion of CD4(+) T cells causes reactivation of murine persistent tuberculosis despite continued expression of interferon gamma and nitric oxide synthase 2. J Exp Med 192: 347-358, 2000

15. Schmid KE, Boszczyk BM, Bierschneider M, Zarfl A, Robert B, Jaksche H: Spondylitis following vertebroplasty: a case report. Eur Spine J 14:895-899, 2005

16. Walker DH, Mummaneni P, Rodts GE Jr: Infected vertebroplasty. Report of two cases and review of the literature. Neurosurg Focus 17:6, 2004

17. Yu SW, Chen WJ, Lin WC, Chen YJ, Tu YK: Serious pyogenic spondylitis following vertebroplasty-A case report. Spine 29: 209-211, 2004 